Aksiologiya: Jurnal Pengabdian Kepada Masyarakat

Vol.4, No.2, Agustus 2020 Hal 241 - 247

ISSN 2528-4967 (print) dan ISSN 2548-219X (online)

\title{
Program Penyuluhan Pra Nikah Perspektif Islam untuk Meningkatkan Pengetahuan mengenai Pernikahan Islami
}

\author{
Karimulloh$^{1}$, Ratih Arruum Listiyandini ${ }^{2}$, Chandradewi Kusristanti ${ }^{3}$ \\ 1,2,3 Fakultas Psikologi Universitas YARSI \\ Email: karimulloh@yarsi.ac.id ${ }^{1}$, ratih.arruum@gmail.com², chandradewi.k@ \\ gmail.com ${ }^{3}$
}

\begin{abstract}
ABSTRAK
Islam mengatur cara memilih pasangan yang ideal dan menjelaskan hak dah kewajiban yang akan dilaksanakan setelah mereka berumah tangga. Namun meningkatnya perceraian di Indonesia adalah sebuah pertanda mengenai ketidaksiapan pasangan suami istri terhadap hak dan kewajiban mereka dalam melaksanakan tugasnya. Penyuluhan persiapan pranikah perpektif Islam ini dilakukan untuk meningkatkan pengetahuan mengenai keluarga yang sakinah, mawaddah wa rahmah sehingga dapat mempersiapkan mereka dalam memilih pasangan hidup dan mengemban tanggung jawab dalam pernikahan. Penyuluhan ini memberikan tema-tema menarik seperti konsep memilih pasangan hidup, proses ta'aruf dan Khitbah, hak dan kewajiban suami istri, serta mempersiapkan keturunan yang sholih dari sisi Islam dan psikologi. Partisipan penyuluhan adalah remaja akhir dan dewasa muda yang belum menikah baik laki-laki maupun perempuan. Hasil penyuluhan menunjukkan adanya peningkatan pengetahuan partisipan mengenai persipan pranikah perspektif Islam.
\end{abstract}

Kata kunci: pra-nikah, pernikahan, islam, penyuluhan

\section{Islamic Perspective Pre-Marriage Extension Program to Increase Knowledge of Islamic Marriage}

\begin{abstract}
Islam regulates how to choose the ideal partner and explains the rights and obligations that will be carried out after they are married. However, the increasing rate of divorce in Indonesia is a sign of the unpreparedness of married couples towards their rights and obligations in carrying out their duties. Education of Islamic perspective premarital preparations has been done done to increase the knowledge of the late adolescents regarding the concept of sakinah, mawaddah, wa rahmah and also to prepare their readiness to choose partner based on Islamic criteria and for being more thoughtful about responsibility in marriage life. This program provides interesting themes such as the concept of choosing a spouse, the process of ta'aruf and khitbah, the rights and obligations of husband and wife, and offspring issues from the side of Islam and psychology. Participants are single late teenagers and young adult, both men and women. Outreach results indicate an increase in participants' knowledge regarding the concept of marriage in Islamic perspective.
\end{abstract}

Key words: pre-marital, marriage, Islam, education 


\section{PENDAHULUAN}

Islam adalah agama yang sempurna. Islam mengatur segala urusan umat manusia dari sejak lahir sampai ke liang lahat. Bahkan seseorang yang ingin memiliki anak yang sukses dunia dan akhirat (sholeh) maka dia harus memilih pasangan hidup yang memiliki visi dan misi dunia dan akhirat. Nabi SAW bersabda yang artinya: "Wanita dinikahi karena empat sebab; karena hartanya, Nasabnya, kecantikannya dan agamanya. Maka pilihlah wanita yang berpegang teguh kepada agamanya agar kamu selamat. (Al-Bukhari, 2013). Seorang lelaki bertanya kepada Hasan bin Ali R.A, "Saya punya putri, siapakah kiranya yang patut menjadi suaminya menurut anda?" Beliau menjawab, "Seseorang laki-laki yang takwa kepada Allah. Sebab jika ia senang ia akan memuliakannya, dan apabila ia benci ia tidak akan berbuat zholim kepadanya". (Faridl, 2007).

Namun berdasarkan data dari Badan Pusat Statistik tahun 2014 jumlah perceraian di Indonesia mencapai 344.237 kasus dan tahun 2015 mencapai 347.256 kasus, sedangkan perceraian di DKI Jakarta pada tahun 2014 mencapai 10.431 kasus dan tahun 2015 mencapai 10.303 kasus. Tingginya tingkat perceraian di Indonesia adalah sebuah pertanda mengenai ketidaksiapan pasangan suami istri terhadap hak dan kewajiban mereka dalam melaksanakan tugasnya. Padahal Nabi Muhammad SAW bersabda Perkara halal yang paling dibenci oleh Allah Ta'alaa adalah menjatuhkan thalaq (cerai). (H.R. Abu Dawud). Dan dalam riwayat lain, Nabi SAW juga bersabda yang artinya Setiap kalian adalah pemimpin, dan setiap kalian akan dimintai pertanggung jawabannya. Maka seorang imam adalah pemimpin dan akan dimintai pertanggung jawabannya. Seorang laki-laki adalah pemimpin atas keluarganya dan ia akan dimintai pertanggung jawabannya. Seorang wanita adalah pemimpin atas rumah suaminya, dan ia pun akan dimintai pertanggung jawabannya. Dan seorang budak juga pemimpin atas harta tuannya dan ia juga akan dimintai pertanggung jawabannya. Sungguh setiap kalian adalah pemimpin dan setiap kalian akan dimintai pertanggungjawabannya. (H.R. Al-Bukhori).

Jika dilihat dari definisinya perceraian merupakan suatu peristiwa perpisahan secara resmi antara pasangan suami-istri dan mereka berketetapan untuk tidak menjalankan tugas dan kewajiban sebagai suami-istri (Dariyo, 2004). Faktor penyebab perceraian bisa dikarenakan 1) kekerasan verbal, 2) masalah ekonomi, 3) keterlibatan penyalahgunaan minuman keras, atau 4) perselingkuhan. Mereka yang telah bercerai tetapi belum memiliki anak, maka perpisahan tidak menimbulkan dampak traumatis psikologis bagi anak-anak. Namun, mereka yang telah memiliki keturunan tentu saja perceraian menimbulkan masalah psiko-emosional bagi anak-anak. Sebagai contoh, hasil penelitian menunjukkan bahwa remaja yang 
mengalamiperceraianorangtuatampak memiliki gejala depresi pada kategori yang perlu diberi perhatian khusus (Listiyandini \& Kusristanti, 2019). Maka dari itu sebelum memasuki ke jenjang pernikahan, baik perempuan maupun laki-laki yang ingin menikah diwajibkan untuk mempersiapkan diri menjadi orang tua yang baik, agar memiliki keluarga yang harmonis dan keturunan yang sholih dan sholihah.

Berdasarkan penjelasan yang telah dipaparkan bahwa perlunya memilih pasangan hidup yang sholih dan menjadi orang tua yang baik. Dengan demikian, para pemuda yang akan memasuki pernikahan, perlu dibekali dengan pengetahuan mengenai pernikahan dan pengasuhan yang Oleh karena itu, penting untuk melakukan pelatihan mengenai persiapan pranikah menurut agama islam. Dengan program ini, partisipan akan diberikan penyuluhan mengenai cara memilih pasangan yang ideal dalam Islam, ta'aruf dan khitbah, hak serta kewajiban suami dan istri, dan adabul jima' serta mempersiapkan keturunan yang shalih dan shalihah menurut perspektifpsikologi. Program yang dilakukan sebelumnya oleh Fitriana dan Listiyandini (2016) pada pasangan dewasa muda yang akan menikah dalam satu tahun ke depan maupun program dari Listiyandini, Fitriana, Kinanti, dan Febriani (2016) pada calon pengantin menemukan bahwa program pelatihan persiapan pranikah terbukti dapat meningkatkan pengetahuan (Fitriana \& Listiyandini, 2016; Listiyandini, Fitriana, Kinanti, dan Febriani, 2016) dan optimisme peserta mengenai pernikahan (Listiyandini, Fitriana, Kinanti, dan Febriani, 2016). Program yang diselenggarakan tersebut merupakan psikoedukasi mengenai hubungan pernikahan, mengatasi konflik, hingga merancang masa depan, melalui sudut pandang psikologi.

Mengingat pentingnya pengetahuan pernikahan yang Islami di samping pengetahuan psikologi pernikahan, maka tujuan dari program penyuluhan pranikah ini yaitu: meningkatkan pengetahuan partisipan di dalam memilih pasangan hidup, berbagi tanggung jawab, serta hak dan kewajiban yang sesuai dengan ajaran Islam. Kemudian manfaat dalam pelatihan ini yaitu, dapat meningkatkan pengetahuan partisipan mengenai anak yang sholeh dari perspektif psikologi maupun Islami. Peningkatan wawasan partisipan mengenai pernikahan, diharapkan menjadi langkah awal sehingga terlahir generasi yang sukses dunia dan akhirat, dan juga meminimalisir terjadinya perceraian di wilayah Jakarta Pusat.

Berdasarkan latar belakang, dapat disimpulkan bahwa umat Islam perlu mengetahui kriteria pasangan hidup yang baik menurut Islam sebelum terjadinya perkawinan supaya terbinanya rumah tangga yang sakinah, mawaddah wa rahmah, dan pada akhirnya terbentuk anak yang dapat membahagiakan orangtuanya dunia dan akhirat sehingga perceraian benar-benarjalanterakhiryang diambil jika terjadi permasalahan. Oleh karena itu, kami memandang penting masalah 
persiapan pra nikah perspektif Islam untuk diangkat, dengan pertanyaan penelitian: Apakah penyuluhan persiapan pra nikah perspektif Islam berpengaruh terhadap pengetahuan mengenai pernikahan Islami?

\section{METODE PENELITIAN Rancangan program}

Kegiatan ini merupakan penyuluhan satu hari yang dimulai dengan pemaparan materi mengenai memilih pasangan hidup yang baik dan benar menurut pandangan islam, kemudian dilanjutkan dengan pemaparan materi kedua yaitu ta'aruf dan khitbah. Selain itu, terdapat dua materi lain yaitu hak serta kewajiban suami istri dan mempersiapkan keturunan yang shalih dan shalihah. Penyuluhan ini menggunakan desain one group pre-test post test. Pada penyuluhan ini tidak adanya kelompok pembanding, namun sebelum dilakukannya pemaparan materi akan diberikan pre-test atau tes awal yang bertujuan untuk mengetahui pemahaman awal partisipan. pre-test diberikan pada dua waktu yang berbeda yaitu saat acara dimulai dan setelah istirahat. Setelah pemaparan materi diberikan, pelaksana memberikan post test guna untuk melihat apakah ada peningkatan antara sebelum diberikan materi dengan sesudah diberikan materi. Post test diberikan pada dua waktu yang berbeda. Post test pertama dilakukan setelah penyampaian materi mengenai memili memilih pasangan hidup yang baik dan benar menurut pandangan islam serta ta'aruf dan khitbah kemudia post test kedua diberikan setelah materi hak serta kewajiban suami istri dan adabul jima' menurut islam. Dalam desain penyuluhan ini, efektivitas diukur berdasarkan kenaikan nilai pre-test partisipan yang dilihat dalam post test.

\section{Partisipan}

Penyuluhan "Persiapan Pranikah Menurut Agama Islam" ini dilakukan di Masjid Cut Meutia. Pada hari pelaksanaan, partisipan yang hadir 73 orang pada sesi pertama dan 61 orang pada sesi kedua. Peserta adalah remaja akhir hingga dewasa muda, yang sudah memiliki calon pasangan maupun belum, dengan rentang usia di atas 18 tahun. Partisipan didapatkan melalui penyebaran undangan yang menggunakan media digital, seperti grup pertemanan online maupun media sosial. Dalam pelaksanaannya, kami juga bekerjasama dengan Remaja Masjid Cut Mutia (RICMA).

\section{Prosedur}

Penyuluhan ini dilakukan pada hari Minggu, 17 April 2019. Sebelum penyuluhan dimulai, partisipan melakukan registrasi kehadiran. Saat melakukan registrasi, partisipan mendapatkan snack dan modul untuk materi pertama dan materi kedua. Penyuluhan ini dimulai pukul 09.30 dengan pembukaan oleh MC kemudian dilanjut pembacaan ayat suci AlQuran oleh anggota RICMA (Remaja Islam Cut Meutia). Acara dilanjutkan dengan sambutan dari perwakilan fakultas Psikologi Universitas YARSI dan perwakilan anggota RICMA. 
Kegiatan ini dilakukan dalam dua sesi dengan model pembelajaran ceramah dan tanya jawab atau diskusi. Sesi pertama terdiri dari dua materi, yaitu materi calon pasangan ideal dalam Islam atau dibuat dengan bahasa milenial menjadi "sudah idealkah kamu?", dan materi konsep ta'aruf dan khitbah diubah bahasa menjadi "nikah? siapa takut!" Sesi kedua juga terdiri dari dua materi, yaitu materi hak dan kewajiban suami isteri atau diubah bahasa menjadi "Kewajibanku adalah hakmu", dan materi mempersiapkan Keturunan yang Sholeh dalam Perspektif Islam dan Psikologi atau diubah bahasa menjadi "Pastikan hubungan intimmu sesuai dengan syariat Islam".

Sesi pertama dimulai dengan pre-test dan selanjutnya diisi dengan materi calon pasangan ideal selama 40 menit, kemudian dilanjutkan dengan tanya jawab selama 10 menit. Pada materi ini pembicara menjelaskan bagaimana memilih pasangan hidup yang ideal menurut Islam, bagaimana cara mendapatkannya dan faktor apa yang harus diutamakan dalam memilih pasangan hidup. Materi kedua pada sesi pertama diisi dengan durasi yang sama seperti materi pertama. Tema yang dijelaskan adalah konsep ta'aruf dan khitbah. Pada materi ini pembicara menjelaskan bagaimana proses ta'aruf yang sesuai dengan Islam, apa tujuan dan manfaatnya, kemudian juga menjelaskan khitbah, baik secara bahasa, istilah, syarat sahnya khitbah dan hukum serta batasan anggota tubuh yang boleh dilihat dalam khitbah. Setelah proses tanya jawab selesai dalam materi kedua ini, partisipan diminta untuk mengisi post test.

Sesi kedua dimulai setelah partisipan istirahat makan siang dan sholat zhuhur. Sebelum materi pertama dimulai, partisipan diminta untuk mengisi pre-test. Adapun materi pertama dalam sesi kedua ini adalah hak dan kewajiban suami isteri. Pemateri menjelaskan apa saja kewajiban suami yang mana hal tersebut merupakan hak bagi sang isteri, dan juga sebaliknya kewajiban isteri yang mana hak bagi suami, serta menjelaskan hak bersama antara suami dan isteri. Materi kedua dalam sesi kedua adalah mempersiapkan keturunan yang sholeh dalam perspektif Islam dan psikologi. Pemateri menjelaskan bagaimana adab berjima' dalam Islam, waktu yang baik untuk bersenggama dan doa serta hal-hal yang perlu diperhatikan. Kemudian dari sisi psikologi dijelaskan bagaimana mempersiapkan generasi yang sholeh masa depan dengan mempunyai visi keluarga dan mempersiapkan diri sebagai orangtua. Acara kemudian dilanjutkan dengan sesi tanya jawab. Setelah sesi tanya jawab selesai, partisipan diminta untuk mengisi post test dan lembar evaluasi. Acara terakhir ialah penutupan oleh MC kemudian dilanjutkan dengan sesi foto.

\section{HASIL DAN PEMBAHASAN}

Metode analisis data dilakukan secara kuantitatif. Analisis dilakukan dengan membandingkan hasil pre-test dan post test partisipan. Perbandingan 
ini kemudian dianalisis dengan metode statistik related samples wilcoxon. Pre-test dan post test sesi pertama yaitu kuesioner yang menanyakan calon pasangan ideal dalam islam serta ta'aruf dan khitbah mengalami peningkatan nilai sebesar 49.03 poin.

Tabel 1 Hasil pre-post tes pengetahuan calon pasangan ideal dalam Islam dan konsep ta'aruf dan khitbah

\begin{tabular}{lccc}
\hline & $\mathrm{N}$ & Mean & $\begin{array}{c}\text { Std. } \\
\text { Deviation }\end{array}$ \\
\hline Pre-test & 72 & 23.1944 & 9.46846 \\
\hline Post-test & 72 & 72.2222 & 18.24885 \\
\hline
\end{tabular}

Pelaksana menggunakan uji beda menggunakanteknikanalisiswilcoxon. Uji beda wilcoxon menunjukkan adanya peningkatan yang signifikan dalam nilai pengetahuan calon pasangan ideal dalam Islam dan konsep ta'aruf dan khitbah dengan nilai signifikan $(\mathrm{p}<, 05)$ (tabel 2). Dapat disimpulkan bahwa terjadinya peningkatan pengetahuan partisipan setelah diberikan materi megenai calon pasangan ideal dalam islam serta ta'aruf dan khitbah.

Tabel 2 Uji beda statistik terhadap pre-post tes pengetahuan calon pasangan ideal dalam Islam dan konsep ta'aruf dan khitbah

\begin{tabular}{ccc}
\hline Materi & Z & Sig \\
\hline
\end{tabular}

Calon pasangan ideal serta konsep $\quad-7.282 \quad .000$ ta'aruf dan khitbah

Pre-test dan post test sesi kedua yaitu kuesioner yang menanyakan tentang hak serta kewajiban suami isteri serta mempersiapka keturunan yang shalih dan shalihah. Pre-test dan post test mengenai kedua materi tersebut mengalami kenaikan seberar 36.39 poin.

Tabel 3 Hasil pre-post tes pengetahuan hak dan kewajiban suami istri serta keturunan shalih

\begin{tabular}{|c|c|c|c|}
\hline & $\mathrm{N}$ & Mean & $\begin{array}{c}\text { Std. } \\
\text { Deviation }\end{array}$ \\
\hline Pre-test & 61 & 53.1148 & 16.48646 \\
\hline Post-test & 61 & 89.5082 & 11.89205 \\
\hline
\end{tabular}
menunjukkan adanya peningkatan nilai pengetahuan partisipan dengan nilai signifikan $(p<, 05)$ (tabel 4). Hal ini dapatdisimpulkan bahwa partisipan mengalami peningkatan pengetahuan mengenai hak dan kewajiban suami istri serta mempersiapkan keturunan yang shalih dan shalihah.

Tabel 4 Uji beda pre-post tes pengetahuan hak kewajiban suami istri dan keturunan sholih

Materi $\quad$ Z Sig

Hak kewajiban suami istri $-6.763 \quad .000$

\section{Diskusi}

Tingginya angka perceraian di Indonesia disebabkan karena beberapa faktor diantaranya ialah perselingkuhan, faktor ekonomi. 70\% orang yang menggugat cerai ialah istri (Panjaitan, 2015). Materi mengenai memilih pasangan calon pasangan ideal menurut islam membahas bahwa salah satu yang dipertimbangkan ketika memilih calon pasangan ideal ialah harta atau ekonominya.

Berdasarkan hasil pre-test dan post test yang diberikan pada sesi 
pertama, didapatkan bahwa terdapat adanya peningkatan skor pengetahuan mengenai konsep pernikahan Islami pada peserta. Berdasarkan paparan diatas, dapat dikatakan bahwa kegiatan penyuluhan yang diberikan cukup berhasil dalam menambah wawasan mengenai hal-hal yang harus dipersiapkan sebelum menikah. Terutama pada sesi pertama karena mengalami kenaikan point yang lebih tinggi dibandingkan pada sesi kedua. Sesi pertama adalah membahas mengenai calon pasangan ideal menurut islam serta ta'aruf dan khitbah. Pada sesi kedua membahas mengenai hak dan kewajiban suami isteri serta mempersiapkan generasi shalih menurut islam dan tinjauannya dalam ilmu psikologi.

\section{SIMPULAN}

Penyuluhan persiapan pra nikah ditemukan efektif untuk meningkatkan pengetahuan peserta mengenai konsep pernikahan islami. Dengan meningkatnya pengetahuan mengenai calon pasangan ideal dalam islam maka akan diharapkan dapat mempersiapkan umat untuk memasuki rumah tangga sakinah, mawaddah wa rahmah, dan pada akhirnya perceraian benar-benar jalan terakhir yang diambil jika terjadi permasalahan.

\section{DAFTAR PUSTAKA}

Al-Bukhari, A.A. (2013). Ensklopedia Hadits: Shahih Al-Bukhari. Jakarta: Almahira.

Dariyo, A. (2004). Memahami Psikologi Perceraian Dalam Kehidupan Keluarga. Psikologi, 2, 94-100.

Faridl, M. (2007). Rumahku Surgaku:
Romantika dan Solusi Rumah Tangga. Jakarta: Gema Insani.

Fitriana, T. S., \& Listiyandini, R. A (2016). Program pelatihan persiapan pra nikah bagi dewasa muda di Jakarta. Kaji Tindak: Jurnal Pemberdayaan Masyarakat, 2(2), 73-80.

Listiyandini, R. A., Fitriana, T. S., \& Febriani,Z. (2016). Peningkatan optimisme dan pengetahuan mengenai pernikahan pada calon pengantin melalui program pelatihan persiapan pra nikah. Prosiding SNaPP: Kesehatan (Kedokteran, Kebidanan, Keperawatan, Farmasi, Psikologi), 2(1), 77-84.

Listiyandini, R. A., \& Kusristanti, C. (2019). Depression and Mindfulness amongAdolescents with Parental Divorce. In $1 s t$ Annual Internatioal Conference on Social Sciences and Humanities (AICOSH 2019). Atlantis Press.

Panjaitan, D. (2015, Juni 06). Inilah Penyebab Perceraian Tertinggi di Indonesia. rievedfromKompasiana:https:// www.kompasiana.com/bangde pan/55094acaa3331122692e39 65/inilah-penyebab-perceraiantertinggi-di-indonesia 